\title{
AVALIAÇÃO DO CONJUNTO MOTOR GERADOR MONOFÁSICO ALIMENTADO COM BIOGÁS PURIFICADO DA FERMENTAÇÃO ANAERÓBIA DE DEJETOS DE SUÍNOS
}

\author{
Neiton Silva Machado ${ }^{1}$, Jadir Nogueira da Silva², Marcus Vinícius Morais de Oliveira ${ }^{3}$, José Márcio Costa
}

\section{RESUMO}

A geração de energia elétrica a partir de dejetos orgânicos da agropecuária ainda é muito incipiente no Brasil. Diante disso, o objetivo deste trabalho foi avaliar a viabilidade técnica da utilização de um conjunto motor gerador, monofásico de $30 \mathrm{kVA}$, para geração de energia elétrica, por meio da combustão do biogás purificado. Utilizaram-se três processos físicos e químicos de remoção do sulfeto de hidrogênio: Filtragem via úmida $(0,1 \mathrm{~m} 3$ de $\mathrm{H}_{2} \mathrm{O}$ mais $20 \mathrm{~kg}$ de $\mathrm{CaO}$ e $10 \mathrm{~kg}$ de carvão vegetal); filtragem via seca $\left(50 \mathrm{~kg}\right.$ de arame liso recozido $\mathrm{n}^{\circ} 06 \mathrm{e} 10 \mathrm{~kg}$ de carvão vegetal); filtragem em série (filtragem via úmida seguido da filtragem via seca) com os recheios dos filtros nas mesmas proporções. Avaliou-se o desempenho do conjunto motor gerador em função do tempo de funcionamento. Com base nos resultados, pode-se concluir que os sistemas de filtragem, em média, reduziram as emissões de $\mathrm{CH}_{4} \mathrm{e}$ $\mathrm{SO}_{2}$ do conjunto motor gerador e mantiveram constantes as emissões de $\mathrm{H}_{2} \mathrm{~S}$. A filtragem via úmida com hidróxido de cálcio possibilitou o maior rendimento teórico e observado do conjunto motor gerador, que foi de $29 \%$ e $12 \%$, respectivamente.

Palavras-chave: $\mathrm{H}_{2} \mathrm{~S}$, metano, purificação

\section{ABSTRACT
ASSESSMENT OF A MONOPHASE GENERATOR ENGINE SET WHICH WAS FUELLED WITH PURIFIED BIOGAS FROM ANAEROBIC FERMENTATION OF SWINE WASTE

The generation of electricity using organic residue from animal production farms is not very well known in Brazil. Therefore, the objective of this study was to evaluate the technical feasibility of using a $30 \mathrm{kVA}$ monophase generator engine set in order to generate electricity by the combustion of purified biogas. It was used three physicochemical processes for removing hydrogen sulphide, which were wet filtration $\left(0.1 \mathrm{~m} 3 \mathrm{H}_{2} \mathrm{O}+20 \mathrm{~kg}\right.$ of CaO and $10 \mathrm{~kg}$ of charcoal); dry filtering (50 kg flat wire annealed No. 06 and $10 \mathrm{~kg}$ of charcoal) and filtering in series (wet filtering followed by dry filtering), fillings the filters with the same proportions. Performance of the generator engine set was evaluated as a function of operating time. Based on the results, it could be concluded that on average the filtering systems reduced emission of $\mathrm{SO}_{2}$ and $\mathrm{CH}_{4}$ of the generator engine set and maintained emission of $\mathrm{H}_{2} \mathrm{~S}$. The wet filtering with calcium hydroxide resulted in the highest theoretical and observed yields for the generator engine set set, which were $29 \%$ and $12 \%$, respectively.

Keyword: $\mathrm{H}_{2} \mathrm{~S}$, methane, purification

Recebido para publicação em 17/04/2013. Aprovado em 26/05/2014.

1 - Eng Agrícola e Ambiental, D.Sc. Prof.Adjunto CEAGRO - UNIVASF, E-mail:neiton.machado@univasf.edu.br

2 - Bacharel em Matemática, Ph.D. Prof Titular. DEA - UFV, E-mail:jadir@ufv.br

3 - Eng Agrícola e Ambiental, D.Sc. Prof Adjunto DE/IT - UFRRJ, E-mail:marvin_moroli@yahoo.com.br

4 - Eng. Agrícola, D.Sc. Prof.Adjunto DEA - UFV, E-mail:jcosta@ufv.br 


\section{INTRODUÇÃO}

A geração de energia elétrica a partir de dejetos orgânicos da agropecuária ainda é muito incipiente no Brasil. Poucas são as alternativas de baixo custo e eficientes para purificação do biogás gerado a partir da fermentação anaeróbica de dejetos da agropecuária. Além disso, é pequeno o número de pesquisadores que demonstram interesse no desenvolvimento de tecnologias sustentáveis de baixo custo e eficientes, para a purificação do biogás originário dos dejetos da agropecuária, em especial a remoção de sulfeto de hidrogênio $\left(\mathrm{H}_{2} \mathrm{~S}\right)$, de modo que o biogás possa ser usado apropriadamente e sem restrições sobre a matriz energética, para fins de geração de eletricidade (VARNERO et al., 2012)

O desenvolvimento de tecnologias e processos para prover o aproveitamento do biogás pode contribuir com a disseminação de seu uso no Brasil, além de ser uma alternativa interessante para empresas que queiram produzir e difundir sistemas de purificação de biogás. Ademais, Lacour et al., (2012).afirmam que o uso do metano ao invés de diesel, em motores de combustão interna, conduz a uma economia de $20 \%$ em emissões de $\mathrm{CO}_{2}$.

O uso do biogás como fonte alternativa para a geração de energia elétrica para diferentes períodos de geração é economicamente viável, embora o aumento da demanda de energia elétrica na propriedade rural aumenta o Valor Presente Líquido (VPL) e diminui o tempo de retorno do investimento (MARTINS; OLIVEIRA, 2011).

Souza et al. (2010) avaliaram o desempenho de um conjunto motor gerador adaptado para biogás contendo, em média, $63 \%$ de metano. Os testes foram realizados com o motor operando, inicialmente, a gasolina na sua versão original e, posteriormente, com o sistema de alimentação à biogás. Para o conjunto motor gerador alimentado à gasolina, na sua versão original, observaram potência média gerada de 840,2 W, com tensão de $109 \mathrm{~V}$ e eficiência do conjunto de $12,14 \%$. Para o conjunto motor gerador operando à biogás e utilizando-se o sistema de alimentação desenvolvido, observaram potência média de $934,59 \mathrm{~W}$, tensão $100,90 \mathrm{~V}$ e eficiência de $8,22 \%$. Os autores concluíram que é possível operar estavelmente o conjunto motor gerador com combustível alternativo, biogás, utilizando o sistema de alimentação desenvolvido, substituindo em $100 \%$ o uso de gasolina.

A geração de energia elétrica a partir do biogás da fermentação anaeróbia de dejetos de suínos é potencialmente viável, do ponto de vista econômico, mas depende diretamente do dimensionamento técnico da demanda de energia elétrica para as diversas atividades da propriedade, frente à oferta de energia do grupo gerador (CERVI et al., 2010). Desta forma, é possível suprir as demandas de energia da propriedade, proporcionando excedentes que possam ser negociados com as concessionárias de energia ou na Câmara de Comercialização de Energia Elétrica (CCEE), tornando a granja suinícola independente energeticamente a partir do uso de biogás (FERRAREZ et al., 2010).

$\mathrm{O}$ custo de produção da energia elétrica gerada com aproveitamento do biogás bruto é composto do capital investido na construção, manutenção do biodigestor e sistema motor gerador. $\mathrm{O}$ biodigestor, operando o ano inteiro, representa cerca de R\$ 200,00/suíno alojado e o conjunto motor gerador, operando durante dez horas diárias ou no horário de ponta (4 horas/dia), R $\$ 440,00 / \mathrm{kW}$ de energia elétrica gerada, valores estes, válidos se ambos, biodigestor e conjunto motor gerador trabalharem em condições adequadas de operação e manutenção, porque quanto menor for o tempo de operação, maior o custo de geração de energia elétrica, aumentando, com isso, o tempo de retorno do investimento. (SOUZA et al., 2004). Ademais, o consumo mínimo de eletricidade para que um sistema seja economicamente viável é de $28 \mathrm{kWh}$ (CERVI et al., 2011).

Konzen (1983) afirma que $1 \mathrm{~m} 3$ de esterco de suínos produz em torno de $50 \mathrm{~m} 3$ de biogás, ou seja, aproximadamente $0,051 \mathrm{~m} 3$ de biogás por $\mathrm{kg}$ de dejeto, sendo $1 \mathrm{~m} 3$ de biogás equivalente a $0,66 \mathrm{~L}$ de diesel ou 0,7 L de gasolina, conforme descrito por Oliveira (1993). Além do mais, as políticas internacionais pertinentes ao desenvolvimento de tecnologias sustentáveis estão cada vez mais exigentes. A União Europeia já definiu um objetivo fixo de substituição, até 2020 , de $20 \%$ por ano da sua energia por sistemas renováveis. Uma grande parte da energia renovável será originária da agricultura e da silvicultura europeia. Pelo menos $25 \%$ de toda a bioenergia no futuro poderá ser originária do biogás produzido a partir de dejetos orgânicos da agropecuária (HOLM-NIELSEN et al., 2009).

\section{REVENG}


Diante do exposto, o objetivo geral deste trabalho foi analisar a viabilidade técnica da utilização de um conjunto motor gerador, monofásico de $30 \mathrm{kVA}$, para geração de energia elétrica, por meio da combustão de biogás purificado da fermentação anaeróbia de dejetos de suínos, utilizando três processos físicos e químicos de remoção do sulfeto de hidrogênio.

\section{MATERIAL E MÉTODOS}

A parte experimental do trabalho foi realizada no Sítio Panorama, localizado no município de Teixeiras - MG, onde está montado um sistema de produção de biogás que utiliza biodigestores de fluxo contínuo, alimentados com dejetos de suínos. A suinocultura é composta por um plantel de 500 matrizes. O biodigestor tem produção estimada de $800 \mathrm{~m} 3$ dia-1 de biogás, para fins de tratamento de resíduos e geração de créditos de carbono.

O conjunto motor gerador foi composto por um motor Ford 6 cilindros e gerador síncrono da marca Kohlbach, 4 pólos, monofásico de $30 \mathrm{kVA}$. $\mathrm{O}$ tempo total do teste foi de $1.200 \mathrm{~h}$, fracionado em quatro baterias de $300 \mathrm{~h}$. As verificações das condições físicas e análise de desempenho foram realizadas diariamente.

$\mathrm{O}$ conjunto motor gerador foi equipado com um sistema de chave seccionadora manual que permitia disponibilizar a energia elétrica gerada na rede de transmissão da propriedade, em substituição à energia fornecida pela Companhia Energética de Minas Gerais (CEMIG).

Um medidor de fluxo da marca Techmeter, modelo Delta G40, Tipo 2040/65 (vazão mínima de 3 m3.h-1 e vazão máxima de 65 m3.h-1 e pressão máxima de trabalho de $1200 \mathrm{kPa}$ ) e uma válvula reguladora de pressão do biogás da marca Maxitrol, com uma pressão máxima de entrada de 5 PSI, foram instalados para medir o fluxo e a pressão de alimentação do biogás.

$\mathrm{O}$ avanço de ignição após o ponto morto superior é um parâmetro crítico para manter a operação de funcionamento do motor suave. O nível necessário de avanço da ignição em motores alimentados a biogás é maior do que em motores alimentados com combustíveis convencionais de 25 a $40^{\circ}$ para atingir uma potência máxima (KOELSCH et al., 1986). Diante disso, o carburador do motor foi adaptado segundo a metodologia de Souza (2004), com avanço de ignição de $45^{\circ}$ para trabalhar nas condições ideais de razão de mistura do ar/biogás.

O óleo do filtro de ar e as velas foram trocados a cada $300 \mathrm{~h}$ de funcionamento do motor de acordo com as recomendações do fabricante, ou seja, ao final de cada bateria de testes.

O painel de controle do conjunto motor gerador era composto por um mostrador de temperatura, tensão, corrente, frequência e horas de funcionamento. $\mathrm{O}$ mostrador de frequência permitia fazer ajuste fino para alcançar os $60 \mathrm{~Hz}$, entretanto, para isso, a rotação do motor deveria ser ajustada para o valor mais próximo de 1800 RPM. A rotação foi monitorada manualmente com o tacômetro da marca Icel, modelo TC 5600.

A temperatura do óleo, água, ar/biogás foram monitoradas por meio de sondas termométricas acopladas a um termômetro digital da marca Icel, modelo TDM890. A temperatura e a umidade relativa do ambiente foram determinadas com o equipamento multifunção digital da marca Insthutherm, modelo THDL400 (\%RH, ${ }^{\circ} \mathrm{C}$, Lux, dB).

Utilizou-se o Medidor Universal de Grandezas (MUG), calibrado para coletar e armazenar os dados referentes à energia elétrica gerada a cada segundo.

Foram adotados quatro tratamentos em função da qualidade do combustível do motor. O biogás de alimentação do motor foi submetido a três sistemas de filtragem diferentes, mais a testemunha (biogás bruto). A descrição dos sistemas e a ordem dos testes de filtragem seguem abaixo:

$1^{\circ}$ Tratamento $\quad($ Trat 01$) \rightarrow$ Filtragem via úmida, utilizando $0,1 \mathrm{~m} 3$ de água mais $20 \mathrm{~kg}$ de óxido de cálcio (cal) e $10 \mathrm{~kg}$ de carvão vegetal, como materiais de recheio do filtro;

$2^{\circ}$ Tratamento (Trat 02) $\rightarrow$ Testemunha (Queima do biogás bruto);

$3^{\circ}$ Tratamento (Trat 03) $\rightarrow$ Filtragem via seca, utilizando $50 \mathrm{~kg}$ de arame liso recozido $\mathrm{n}^{\circ} 06$ (aproximadamente 3.000 metros) e $10 \mathrm{~kg}$ de carvão vegetal, como materiais de recheio do filtro;

$4^{\circ}$ Tratamento $\quad$ (Trat 04) $\rightarrow$ Filtragem em série: via úmida com hidróxido de cálcio seguido da via seca com arame liso recozido $n^{\circ} 06$ e carvão vegetal, nas mesmas proporções dos tratamentos 01 e 03 . 
As primeiras $100 \mathrm{~h}$ de funcionamento do motor, antes dos testes de longa duração $(300 \mathrm{~h} /$ tratamento) foram consideradas como período de amaciamento do conjunto motor gerador. Durante esse período de amaciamento, o conjunto motor gerador estava fornecendo toda a energia elétrica necessária aos galpões de maternidade da granja. O período de maior demanda energética neste setor da granja era à noite, para realizar o aquecimento dos leitões. Este foi o motivo pelo qual se optou por coletar os valores de Tensão, Corrente e Potência, na saída do gerador, das $18 \mathrm{~h} 00 \mathrm{~min}$ até às $06 \mathrm{~h} 00$ min, totalizando $720 \mathrm{~min}$ consecutivos de coleta e armazenamento de dados.

No período de amaciamento foi possível fazer os ajustes da tensão de saída do gerador, para $240 \mathrm{~V}$, no intuito de atender a queda de tensão dos ramais de distribuição da propriedade. Após o período de amaciamento, realizou-se uma limpeza do motor, trocaram-se as velas de ignição os filtros de óleo e ar, coletou-se uma amostra do óleo lubrificante para análise da deposição de metais, e deu início aos testes de longa duração.

Entretanto, quando iniciou os testes de longa duração com o sistema de filtragem acoplado, por motivo de falhas no sistema elétrico da propriedade, não foi possível continuar substituindo $100 \%$ o fornecimento de energia elétrica da concessionária CEMIG. Desta forma, para continuarmos o trabalho instalou-se uma bateria de lâmpadas incandescente (54 lâmpadas $200 \mathrm{~W} / 220 \mathrm{~V}$ ) para absorver a energia gerada, totalizando uma carga constante de 10,8 kVA e corrente de, aproximadamente, $50 \mathrm{~A}$.

A potência teórica do motor foi calculada por meio da equação.1:

$\mathrm{P}_{\mathrm{t}}=\mathrm{k} \cdot \mathrm{P}_{\mathrm{c} .} \cdot \mathrm{C}_{\mathrm{h}}$

em que,

$\mathrm{P}_{\mathrm{t}}=$ potência teórica do motor, em cv;

$\mathrm{k}=$ constante de ajuste de unidades $\mathrm{k}=427 /$

$(3600.75)=0,00158427$ é o equivalente mecânico do calor, em kg.kcal-1;

$\mathrm{P}_{\mathrm{c}}=$ poder calorífico do combustível, em kcal.kg-1; e $\mathrm{C}_{\mathrm{h}}=$ consumo horário de combustível, em kg.h-1
Os rendimentos do conjunto motor gerador foram calculados pela razão entre a potência elétrica de saída e a potência teórica disponível pelo combustível (\% de Metano no Biogás) na entrada. Considerou-se o poder calorífico inferior do metano, de 35.880 kJ.m-3 (8570 kcal.m-3), e a massa específica do mesmo, de 0,6504 kg.m-3 (Equação 2).

$n_{\mathrm{cg}}=\frac{\mathrm{P}_{\mathrm{s}}}{\mathrm{P}_{\mathrm{e}}} \cdot 100$

em que,

$\eta_{\mathrm{cg}}=$ Rendimento do conjunto motor gerador, \%;

$\mathrm{P}_{\mathrm{s}}=$ Potencia de saída, $\mathrm{kVA}$; e

$\mathrm{P}_{\mathrm{e}}=$ Potência de entrada, $\mathrm{kVA}$.

No cálculo do rendimento teórico do conjunto motor gerador, considerou-se a potência de saída igual a potência total do gerador, multiplicada por um fator de potência de 0,92 . Já no cálculo do rendimento observado de conversão do sistema motor gerador, considerou-se a potência de saída 10,8 kVA igual à potência da bateria de lâmpadas instaladas (54 lâmpadas de 220 V/200 W).

Foi calculado o consumo horário, por meio das equações 3 e 4 .

$$
\begin{aligned}
& C_{h}=\frac{V}{t} \\
& C_{h}=\frac{M}{t}
\end{aligned}
$$

em que,

$\mathrm{C}_{\mathrm{h}}=$ consumo horário, $\mathrm{m} 3 \mathrm{~h}-1$;

$\mathrm{V}=$ volume de combustível consumido, $\mathrm{m} 3$;

$\mathrm{M}=$ massa de combustível consumido, $\mathrm{kg}$;

$\mathrm{T}=$ tempo de duração do ensaio, $\mathrm{h}$.

A substituição do lubrificante e as demais manutenções preventivas foram realizadas de acordo com a recomendação do fabricante. A cada $300 \mathrm{~h}$ de funcionamento do motor retirava-se uma

\section{REVENG}


amostra do óleo lubrificante para análises físicoquímicas, realizadas no Laboratório de Ensaios de Motores do CETEC-MG, em Belo Horizonte.

As análises físic as e químicas realizadas foram: Viscosidade Cinemática, Ponto de Fulgor, Índice de Base (TBN), Insolúveis em Pentano, pH e Porcentagem de Água.

A Viscosidade Cinemática foi determinada segundo os critérios da norma ASTM D-445. O Ponto de Fulgor foi determinado segundo os critérios da norma ASTM D92, que atende a NBR 11341. Índice ou Número de Base, o TBN foi determinado segundo a norma ASTM D664, que atende a NBR 14448. Os Insolúveis em Pentano foram determinados segundo os critérios da norma ASTM D893, que atende a NBR 14953. A Porcentagem de Água por Destilação foi determinada pelo critério da norma ASTM D95, que atende a NBR 14236.

As análises e avaliações dos desgaste metálico e aditivação foram realizadas com base nos seguintes elementos químicos: Alumínio, Bário, Boro, Cálcio, Chumbo, Cobre, Cromo, Estanho, Ferro, Fósforo, Níquel, Magnésio, Molibdênio, Prata, Silício, Sódio, Titânio, Vanádio, Zinco e quantidade de poeira.

A caracterização dos gases de exaustão teve como finalidade conhecer as proporções e os tipos de gases que foram emitidos pelo motor. Os gases de maior interesse foram: $\mathrm{H}_{2} \mathrm{~S}, \mathrm{SO}_{2}, \mathrm{NO}_{2}, \mathrm{CO}$, $\mathrm{CO}_{2}, \mathrm{O}_{2}, \mathrm{CH}_{4}$. As análises foram feitas durante os testes de desempenho de longa duração, sendo os gases monitorados por meio de detectores portáteis GasAlert, modelo MICRO5 e MICRO5IR, diariamente durante todo o período experimental.

Após o término das $1.200 \mathrm{~h}$ de funcionamento do motor, o mesmo foi enviado à oficina mecânica para análise e manutenção. A equipe de técnicos da oficina mecânica efetuou a desmontagem do motor, fotografando as principais peças, e emitiu o laudo técnico.

A oficina mecânica contratada para realizar os serviços foi a Retífica Rio Branco, situada na cidade de Visconde de Rio Branco-MG. As medições realizadas para verificação dos desgastes foram: no cilindro, pistão, eixo virabrequim, biela, bucha da biela e válvulas. A análise visual das peças internas do motor foi realizada para verificação de anormalidades, desgastes excessivos e acumulo de resíduos da combustão.

A manutenção preventiva do conjunto motor gerador foi realizada de acordo com o manual do fabricante, inspecionada pela equipe da empresa Portal do Agronegócio.

Os dados referentes à avaliação de desempenho do motor foram analisados por meio de estatística descritiva.

\section{RESULTADOS E DISCUSSÕES}

Os valores mínimos, máximos e médios dos parâmetros tensão, corrente e potência (Quadro 1), apresentaram coeficiente de variação inferior a $15 \%$. Segundo Gomes (1990), este valor pode ser classificado como uma variação média a baixa. Além disso, o sistema de geração conseguiu alimentar a carga de forma constante e uniforme, independente das oscilações ocorridas na produção do biogás.

Foram verificadas pequenas oscilações nos parâmetros tensão, corrente e potência (Figura 1) durante o teste de amaciamento do conjunto motor gerador. A tensão apresentou valores médios inferiores a $219 \mathrm{~V}$ durante os testes preliminares, caracterizando a necessidade de aumentar a mesma para suprir as quedas de tensões na linha de transmissão interna da propriedade que liga o conjunto motor gerador às cargas consumidoras, as quais exigem tensão de alimentação de 220 V. A regulagem da tensão de saída foi realizada

Quadro 1. Parâmetros medidos com o Medidor Universal de Grandezas MUG

\begin{tabular}{cccc}
\hline Estatística & Tensão $(\mathrm{V})$ & Corrente $(\mathrm{A})$ & Potência $(\mathrm{kVA})$ \\
\hline Mínimo & 199 & 15 & 3,3 \\
Máximo & 253 & 93 & 22 \\
Média & 219 & 82 & 18 \\
CV (\%) & 5,4 & 14,2 & 14,4 \\
\hline
\end{tabular}

Sendo: CV- Coeficiente de variação 


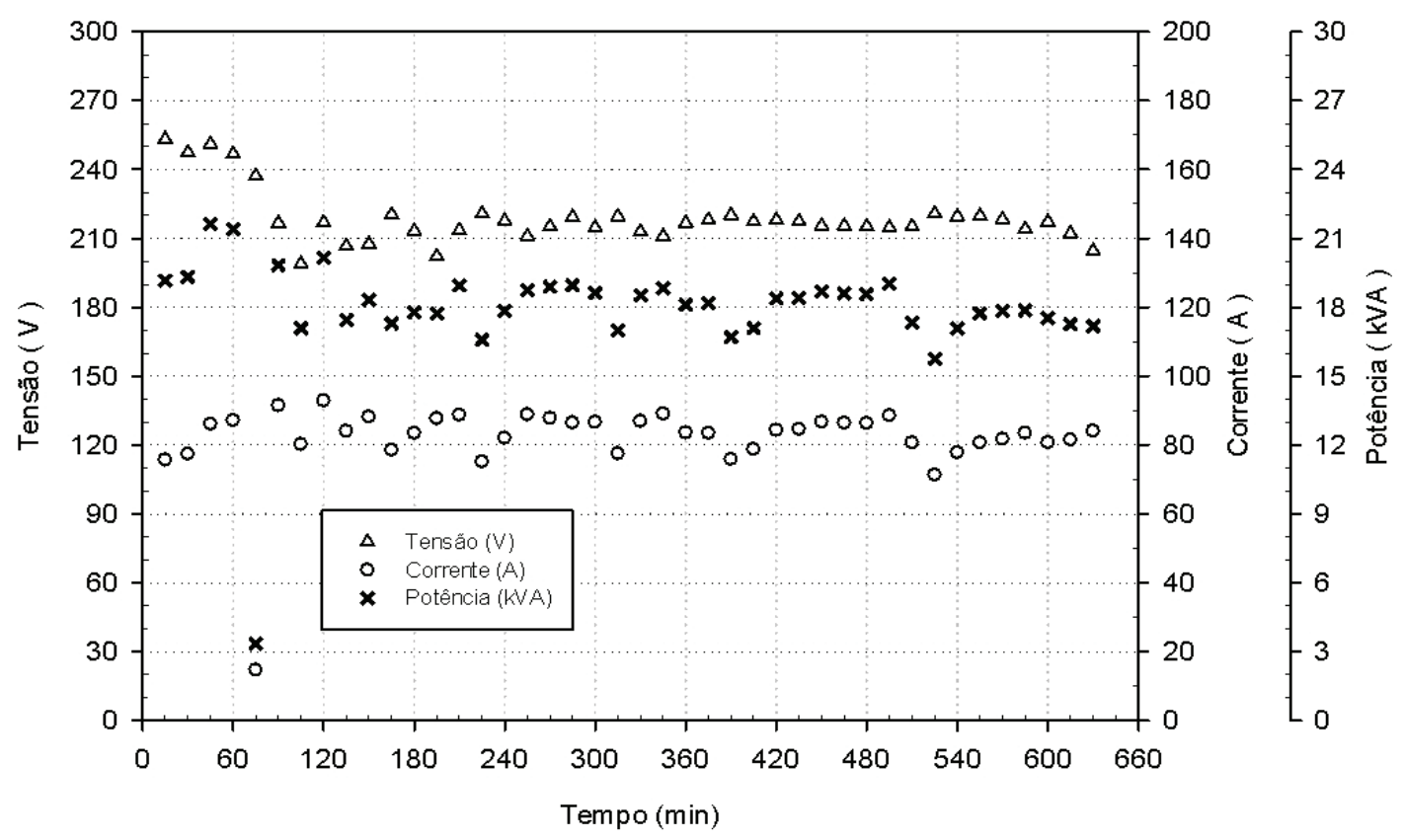

Figura 1. Tensão, corrente e potência em função do tempo de funcionamento do conjunto motor gerador.

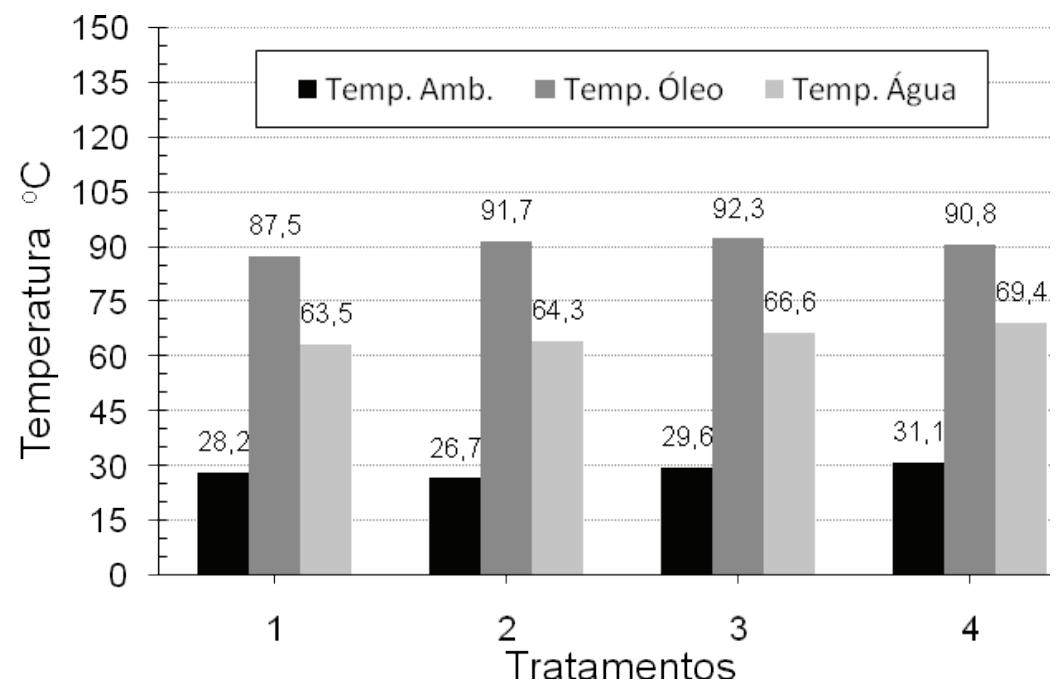

Figura 2. Temperatura média do ar ambiente, óleo lubrificante e água de resfriamento do motor, para cada tratamento.

ajustando-se os potenciômetros "trimpot" da placa eletrônica do gerador, de forma que a tensão gerada aumentasse para $240 \mathrm{~V}$, solucionando o problema de queda de tensão da linha de transmissão.

Pode-se observar que o comportamento médio da temperatura do ar ambiente, temperatura do óleo lubrificante e da água de resfriamento do motor (Figura 2), não apresentaram alterações expressivas ao longo do período experimental, para ambos os tratamentos.

Os resultados das análises e a metodologia utilizada para caracterização das propriedades físicas e químicas do óleo lubrificante utilizado em cada tratamento encontram-se representados na Quadro 2. Estes indicaram que todos os parâmetros físico-químicos analisados encontramse dentro dos limites considerados normais, exceto a porcentagem de água no tratamento 02 . 
Quadro 2. Análise física e química do lubrificante

\begin{tabular}{|l|l|c|c|c|c|c|c|}
\hline Ensaio & Método & Óleo Limpo & Amaciamento & Trat 01 & Trat 02 & Trat 03 & Trat 04 \\
\hline Viscosidade cSt a 40 $\mathrm{C}$ & ASTM-D-445 & 154,36 & 153,85 & 150,27 & 150,21 & 151,94 & 146,64 \\
\hline Ponto de Fulgor VA ${ }^{\circ} \mathrm{C}$ & ASTM-D-92 & 237,00 & 224,00 & 235,00 & 231,00 & 231,00 & 234,00 \\
\hline TBN mg KOH.g-1 & ASTM-D-664 & 3,83 & 1,51 & 1,04 & 1,13 & 2,70 & 1,98 \\
\hline pH Inicial (TBN) & & 8,20 & 6,90 & 6,68 & 6,68 & 6,74 & 7,00 \\
\hline Insolúveis em Pentano & ASTM-D-893 & 0,40 & 0,23 & 0,22 & 0,20 & 0,22 & 0,46 \\
\hline Água \% volume & ASTM-D-95 & 0,00 & 0,00 & 0,00 & 0,10 & 0,00 & 0,00 \\
\hline
\end{tabular}

O valor de TBN, para ambos os tratamentos, foi considerado normal pelo laudo do laboratório, entretanto, verifica-se que no trat 01 este parâmetro apresentou valor inferior aos demais tratamentos. Isso se justifica pela composição química do recheio do filtro (hidróxido de cálcio), pois o TBN indica a quantidade de ácido, expressa em $\mathrm{mg}$ equivalente de $\mathrm{KOH}$, necessária para neutralizar todos os constituintes básicos (alcalinos) em $1,0 \mathrm{~g}$ de óleo. Qualquer óleo, cujo $\mathrm{pH}$ esteja compreendido entre valores 4,0 e 11,0, apresentará um TBN, expresso em mg KOH.g-1, equivalente à quantidade de ácido necessária para levar o $\mathrm{pH}$ do valor em que está até o pH 4,0, e um TAN expresso em mg KOH.g-1 necessário para elevar o pH até o limite superior, $\mathrm{pH} 11,0$.

O resultado das análises de desgaste metálico e aditivação (Quadro 3) reprovaram todas as amostras de todos os tratamentos, sugerindo a substituição imediata do óleo lubrificante, pois o óleo apresentava concentrações de metais acima dos limites considerados normais.

Observa-se que a concentração de alumínio, cálcio, chumbo, cobre, cromo, ferro, níquel, silício e sódio presentes no óleo lubrificante foram os que apresentaram maiores acréscimos quando comparada ao óleo limpo, fortalecendo a hipótese do desgaste por atrito das peças constituintes do motor. Entretanto, observou-se que bário, boro, fósforo, magnésio, prata, titânio, vanádio e zinco apresentaram pequenas ou nenhuma variação na concentração entre os tratamentos e em relação à testemunha (óleo limpo).

Ademais, apenas o estanho e o molibdênio apresentaram um comportamento diferente dos demais elementos. O estanho apresentou valor alto para o tratamento 01 , fato que possivelmente pode ser explicado pela quantidade de poeira encontrada no óleo para este tratamento. Já o molibdênio apresentou um comportamento que não se conseguiu explicar, pois apresentou concentrações muito distintas entre os tratamentos e a testemunha.

Sabe-se que, para melhor identificação das fontes de acréscimo dos elementos químicos no óleo lubrificante há necessidade de quantificar o desgaste e a composição química das peças constituintes do motor. $\mathrm{O}$ desgaste pode ser verificado no Quadro 4, entretanto a composição química das peças não foi possível ser quantificada neste trabalho.

$\mathrm{O}$ desgaste das peças constituintes do motor (Quadro 4) caracterizou o desgaste como normal para o tempo de uso do motor, embora as folgas entre haste e cilindro, folga do óleo da bucha de comando e a folga do óleo do eixo fixo (virabrequim) tenham apresentado valores superiores aos nominais, no laudo da retífica. Entretanto, foi verificado grande calo no cilindro numero 01 , fato este, atribuído ao desalinhamento da biela, sendo que os demais cilindros apresentaram características visuais normais. Desta forma, optou-se por não fazer retífica no motor. 
Quadro 3. Análise de Desgaste Metálico e Aditivação no óleo lubrificante utilizado no motor à biogás

\begin{tabular}{|c|c|c|c|c|c|c|}
\hline Parâmetros & Óleo Limpo & Amaciamento & Trat 01 & Trat 02* & Trat 03 & Trat 04 \\
\hline Alumínio & 0,40 & 11,70 & 13,50 & 14,40 & 15,60 & 3,80 \\
\hline Bário & 0,00 & 0,00 & 0,00 & 0,00 & 0,00 & 0,00 \\
\hline Boro & 0,10 & 0,00 & 0,10 & 0,20 & 0,10 & 0,10 \\
\hline Cálcio & 144,00 & 222,00 & 211,00 & 229,00 & 250,00 & 135,00 \\
\hline Chumbo & 0,00 & 1,40 & 9,70 & 3,30 & 0,80 & 0,00 \\
\hline Cobre & 0,00 & 3,90 & 12,40 & 3,50 & 2,50 & 0,70 \\
\hline Cromo & 0,00 & 3,70 & 5,30 & 4,00 & 4,00 & 1,30 \\
\hline Estanho & 0,00 & 0,00 & 3,70 & 0,00 & 0,00 & 0,00 \\
\hline Ferro & 0,00 & 40,60 & 56,60 & 45,60 & 40,40 & 26,00 \\
\hline Fósforo & 1299,00 & 1236,00 & 1041,00 & 1315,00 & 1376,00 & 1236,00 \\
\hline Magnésio & 767,00 & 871,00 & 691,00 & 885,00 & 992,00 & 770,00 \\
\hline Molibdênio & 1,10 & 0,00 & 0,30 & 0,00 & 0,60 & 0,00 \\
\hline Níquel & 0,00 & 0,30 & 0,70 & 0,60 & 0,90 & 0,10 \\
\hline Prata & 0,00 & 0,00 & 0,00 & 0,00 & 0,00 & 0,00 \\
\hline Silício & 3,30 & 14,10 & 44,80 & 12,70 & 9,30 & 6,00 \\
\hline Sódio & 1,30 & 16,60 & 30,30 & 11,80 & 8,20 & 3,60 \\
\hline Titânio & 0,00 & 0,00 & 0,00 & 0,00 & 0,00 & 0,00 \\
\hline Vanádio & 0,20 & 0,00 & 0,00 & 0,00 & 0,20 & 0,00 \\
\hline Zinco & 1372,00 & 1670,00 & 1371,00 & 1708,00 & 1807,00 & 1347,00 \\
\hline $\begin{array}{l}\text { Quantidade de } \\
\text { Poeira }\end{array}$ & Ausente & Ausente & Grande & Ausente & Ausente & Ausente \\
\hline
\end{tabular}

*Tratamento 02 motor gerador alimentado com biogás bruto

Quadro 4. Desgastes das peças constituintes do motor durante o período experimental

\begin{tabular}{lcc}
\hline Peças & Medidas Nominais (mm) & Medidas Observadas (mm) \\
\hline Diâmetro dos Pistões & 101,60 & 101,57 \\
Diâmetro do Eixo Fixo (Virabrequim) & $60,91-60,93$ & \\
Diâmetro do Eixo Movel (Virabrequim) & $53,91-53,93$ & 51,25 \\
Diâmetro do Eixo Comando de Válvulas & & $0,08-0,10$ \\
Folga entre Pistão e Cilindro & 0,04 & $0,05-0,06$ \\
Folga entre Haste e Guia & $0,02-$ & 0,09 \\
Folga do Óleo Bucha de Comando & $0,02-0,12$ & 0,07 \\
Folga do Óleo Eixo Fixo (Virabrequim) & $0,02-0,06$ & $0,04-0,07$ \\
Folga do Óleo Eixo Movel (Virabrequim) & $0,02-0,04$ & \\
\hline
\end{tabular}

Observação: O primeiro cilindro estava danificado com $0,4 \mathrm{~mm}$ de folga

324 REVENG

317-330p. Engenharia NA Agricultura, VIÇOSA - MG, V.22 N.4, JULHO / AGOSTO 2014 
A concentração média e o coeficiente de variação dos gases de escape para todos os tratamentos (Quadro 5) apresentou pouca variação na concentração do oxigênio, fato que caracteriza a ocorrência de uma boa combustão, tendo em vista que a concentração média de metano nos gases de escape foi baixa.

Cacua et al. (2012), avaliando os efeitos do ar enriquecidocom oxigênio emmotores estacionários, utilizando o biogás como combustível primário, concluíram que pequenas adições de $\mathrm{O}_{2}$ no ar de combustão melhora a estabilidade de combustão do motor biogás-diesel e que o $\mathrm{O}_{2}$ adicional serve para atenuar os efeitos negativos de $\mathrm{CO}_{2}$ na combustão, tais como diminuição global na mistura de gásar, temperatura e baixas velocidades de queima de biogás em relação ao metano. Além disso, os autores afirmam que o enriquecimento de oxigênio é uma técnica viável para o motor alimentado com diesel-biogás com cargas leves, devido à melhoria das características de desempenho, tais como eficiência térmica, diminuição no atraso de ignição, taxas de combustão elevadas, bem como diminui as emissões de metano.

A variação das concentrações do metano, ácido sulfídrico e dióxido de enxofre encontram-se representado na Figura 3. Verifica-se que ambos os tratamentos reduziram a emissão de metano e de dióxido de enxofre na saída do escapamento, embora a concentração de ácido sulfídrico tenha se mantido constante para ambos os tratamentos e a testemunha. Porpatham et al. (2008), avaliando a influência da redução da concentração de $\mathrm{CO}_{2}$ do biogás no desempenho e nas emissões em motor de combustão interna, afirmam que redução do nível de $\mathrm{CO}_{2}$ em $10 \%$ parece ser suficiente para reduzir os níveis de hidrocarbonetos (HC) e os níveis de NO. Ademais, a redução da potência e torque é causada em grande parte pela perda de energia produzida com o aumento da concentração de $\mathrm{CO}_{2}$ (GONZALEZ et al., 2008).

Gonzalez et al. (2008), avaliando experimentalmente um motor de ignição por centelha e utilizando o biogás como combustível, concluíram que o aumento da percentagem de $\mathrm{CO}_{2}$ na mistura fez com que o ângulo de ignição aumentasse, reduzindo a potência máxima e o torque e emissões de escape reduzidas.

$\mathrm{O}$ tempo de funcionamento, volume de biogás, massa de biogás, volume de metano consumido e energia teórica disponível (Quadro 6), apresentaram pequena variação na quantidade de energia teórica disponível entre os tratamentos, devido à variação no tempo de funcionamento do sistema. O tratamento 04 funcionou somente 92,6 $\mathrm{h}$, porque a partir deste tempo o filtro já estava saturado, não justificando mais o funcionamento do sistema.

Quadro 5. Concentrações dos gases de escape nas condições de temperatura e pressão de $25^{\circ} \mathrm{C}$ e 101.325 Pa.

\begin{tabular}{|c|c|c|c|c|c|c|c|c|}
\hline Tratamentos & Estatística & $\mathrm{O}_{2}$ & $\begin{array}{l}\mathrm{CH}_{4} \\
----\end{array}$ & $\mathrm{CO}_{2}$ & $\mathrm{CO}$ & $\begin{array}{r}\mathrm{H}_{2} \mathrm{~S} \\
-\mathrm{ppm}\end{array}$ & $\mathrm{SO}_{2}$ & $\mathrm{NO}_{2}$ \\
\hline \multirow{2}{*}{ Trat 01} & Média & 16,9 & 0,3 & 18320,0 & 171,7 & 18,8 & 35,6 & 6,0 \\
\hline & CV (\%) & 7,7 & 47,1 & 30,2 & 25,2 & 70,2 & 49,2 & 52,6 \\
\hline \multirow{2}{*}{ Trat 02} & Média & 17,7 & 0,5 & 17100,0 & 146,6 & 18,1 & 63,1 & 5,7 \\
\hline & CV (\%) & 4,9 & 47,1 & 17,6 & 20,8 & 55,2 & 117,0 & 35,2 \\
\hline \multirow{2}{*}{ Trat 03} & Média & 17,6 & 0,3 & 16250,0 & 225,7 & 18,8 & 49,3 & 3,8 \\
\hline & CV (\%) & 5,2 & 79,5 & 27,9 & 54,4 & 59,4 & 55,7 & 55,7 \\
\hline \multirow{2}{*}{ Trat 04} & Média & 17,9 & 0,3 & 15075,0 & 123,5 & 16,4 & 47,9 & 4,0 \\
\hline & CV (\%) & 4,6 & 94,3 & 19,2 & 5,2 & 66,8 & 83,1 & 42,8 \\
\hline
\end{tabular}

Sendo: CV- Coeficiente de variação ; 


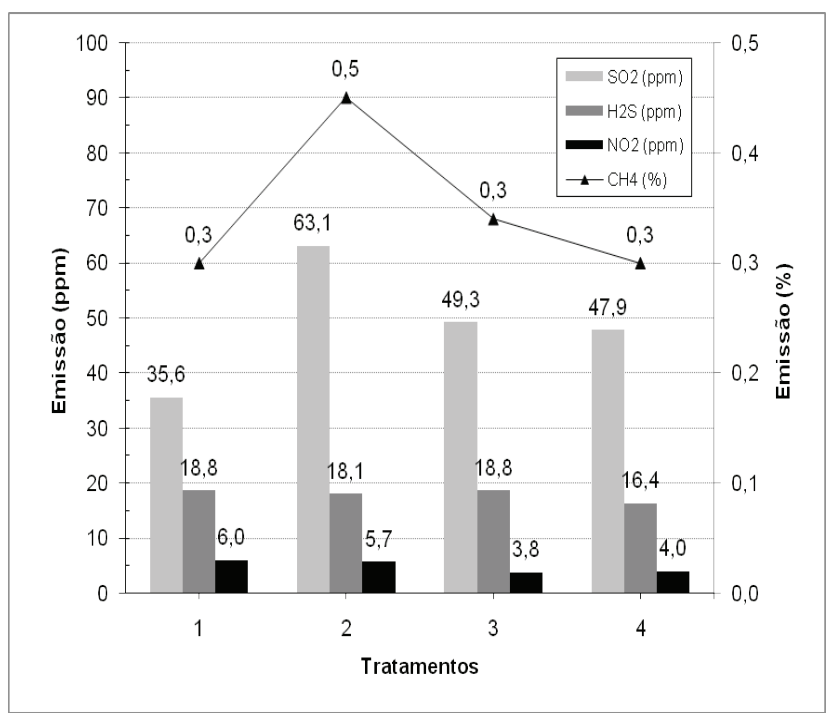

Figura 3. Comportamento da concentração média dos gases de escape $\mathrm{SO}_{2} \mathrm{H}_{2} \mathrm{~S} \mathrm{NO}_{2}$ e $\mathrm{CH}_{4}$ em cada tratamento.

Quadro 6. Tempo de funcionamento, volume de biogás, massa de biogás e metano consumidos, e energia teórica disponível.

\begin{tabular}{cccccc}
\hline Tratamentos & $\begin{array}{c}\text { Tempo de } \\
\text { Funcionamento do } \\
\text { Motor (h) }\end{array}$ & $\begin{array}{c}\text { Volume de Biogás } \\
\text { Consumido }\left(\mathrm{m}^{3}\right)\end{array}$ & $\begin{array}{c}\text { Volume } \\
\text { de Metano } \\
\text { Consumido }\left(\mathrm{m}^{3}\right)\end{array}$ & $\begin{array}{c}\text { Massa de } \\
\text { Metano } \\
\text { Consumido }(\mathrm{kg})\end{array}$ & $\begin{array}{c}\text { Energia Teórica } \\
\text { Disponível } \\
(\mathrm{kWh})\end{array}$ \\
\hline Trat 01 & 302,6 & 3474,1 & 2991,0 & 1945,4 & 29811,2 \\
Trat 02 & 315,3 & 3825,5 & 3332,2 & 2167,3 & 33211,5 \\
Trat 03 & 274,8 & 3425,3 & 2769,8 & 1801,5 & 27606,5 \\
Trat 04 & 92,6 & 1141,6 & 987,0 & 642,0 & 9630,0 \\
\hline
\end{tabular}

Para o consumo de biogás e de metano e a potência teórica do motor (Quadro 7), verificouse pequena diferença no consumo de combustível do tratamento 01, quando comparado aos demais. Pode-se afirmar que o consumo de combustível foi praticamente constante, para ambos os tratamentos, caracterizando um bom funcionamento do conjunto, já que a carga do sistema era praticamente constante (10,8 kVA).

A diferença de consumo de combustível no tratamento 01 é atribuída às oscilações na produção e na pressão do biogás dentro do biodigestor, fato que afetou diretamente a alimentação do conjunto motor gerador. Entretanto, este problema foi corrigido adicionando-se uma válvula reguladora de pressão após o sistema de filtragem.
Para a potência teórica disponível e o rendimento teórico observado em cada tratamento (Quadro 8), observa-se que o tratamento 01 (filtragem com hidróxido de cálcio) apresentou maior rendimento médio quando comparado aos demais tratamentos, fato explicado pelo aumento na concentração de metano e redução de dióxido de carbono, constatados após a filtragem do biogás neste tratamento.

Embora o coeficiente de variação esteja acima de 10 para ambos os tratamentos, podemos afirmar que o sistema comportou-se bem quanto ao parâmetro rendimento. Souza et al. (2010), avaliando o desempenho de um conjunto motor gerador adaptado a biogás, concluiram que a 
Quadro 7. Consumo horário de biogás e metano e potência teórica do motor

\begin{tabular}{ccccc}
\hline Tratamentos & $\begin{array}{c}\text { Consumo horário de } \\
\text { Biogás } \\
(\mathrm{m} 3 . \mathrm{h}-1)\end{array}$ & $\begin{array}{c}\text { Consumo horário de } \\
\text { Metano } \\
(\mathrm{m} 3 . \mathrm{h}-1)\end{array}$ & $\begin{array}{c}\text { Consumo horário de } \\
\text { Metano } \\
(\mathrm{kg} . \mathrm{h}-1)\end{array}$ & $\begin{array}{c}\text { Potência Teórica do } \\
\text { Motor } \\
(\mathrm{cv})\end{array}$ \\
\hline Trat 01 & 11,5 & 9,9 & 6,4 & 87,1 \\
Trat 02 & 12,1 & 10,6 & 6,9 & 93,1 \\
Trat 03 & 12,5 & 10,1 & 6,6 & 88,8 \\
Trat 04 & 12,3 & 10,7 & 6,9 & 93,9 \\
\hline
\end{tabular}

Sendo: Massas especificas calculadas para temperatura média de $27^{\circ} \mathrm{C}$ e pressão de 1 atm $\mathrm{CH}_{4}(0,6504 ; \mathrm{kg} \cdot \mathrm{m}-3) ; \mathrm{CO}_{2}$ (1,7886 kg.m-3); H $\mathrm{S}$ (1,3821 kg.m-3) e Biogás (0,9142 kg.m-3);

Quadro 8. Rendimento teórico e observado do conjunto motor gerador em cada tratamento

\begin{tabular}{ccccc}
\hline Tratamentos & Estatística & $\begin{array}{c}\text { Potência Teórica } \\
\text { Disponível }(\mathrm{kW})\end{array}$ & Rendimento Teórico & $\begin{array}{c}\text { Rendimento } \\
\text { Observado }\end{array}$ \\
\hline \multirow{2}{*}{ Trat 01 } & Média & 99,85 & 0,29 & 0,12 \\
& CV (\%) & 30,11 & 24,28 & 26,31 \\
\hline \multirow{2}{*}{ Trat 02 } & Média & 103,52 & 0,28 & 0,11 \\
& CV (\%) & 18,69 & 21,55 & 21,55 \\
\hline \multirow{2}{*}{ Trat 03 } & Média & 99,02 & 0,28 & 0,11 \\
& CV (\%) & 38,65 & 38,66 & 38,66 \\
\hline \multirow{2}{*}{ Trat 04 } & Média & 113,99 & 0,25 & 0,10 \\
& CV (\%) & 20,42 & 22,94 & 22,94 \\
\hline
\end{tabular}

Sendo: CV- Coeficiente de variação

eficiência média do conjunto foi de $8,22 \%$, enquanto que o mesmo conjunto, operando com gasolina, obteve uma eficiência de $12,3 \%$. Entretanto, Marques (2012), avaliando a produção de biogás proveniente dos dejetos suínos e a geração de energia elétrica utilizando o biogás como fonte primária de energia, concluiu que o consumo específico médio de biogás no motor gerador de $76 \mathrm{~kW}$ foi de $0,68 \mathrm{~m} 3 . \mathrm{kWh}-1$ e com uma eficiência de $22,21 \%$.

Por meio da (Figura 4), observa-se que o comportamento gráfico de ambos os rendimentos (teórico e observado) foram similares ao longo do período experimental. Koelsch et al. (1986), avaliando a cogeração de energia elétrica e calor a partir do biogás com teor de sulfeto de hidrogênio, em média entre 3000 e 4000 ppm., durante 2500 $\mathrm{h}$ de funcionamento do sistema, concluíram que a eficiência elétrica (produção de energia elétrica / poder calorífico inferior do biogás) atingiu um pico de $26 \%$ entre uma relação de equivalência arcombustível de 0,8 e 0,9 . Os autores afirmam que a eficiência elétrica é consistentemente maior para razão ar-combustível baixa e durante a operação do motor perto da carga nominal.

Além das considerações de eficiência energética, as unidades de biogás têm um impacto ambiental global baixo. Por isso são alternativas interessantes para as fontes de energia, como locais de produção de eletricidade (LACOUR et al., 2012). Ademais, vale ressaltar que os esforços para fortalecer os mecanismos institucionais para o desenvolvimento sustentável devem abordar três pilares: econômico, social e ambiental. 

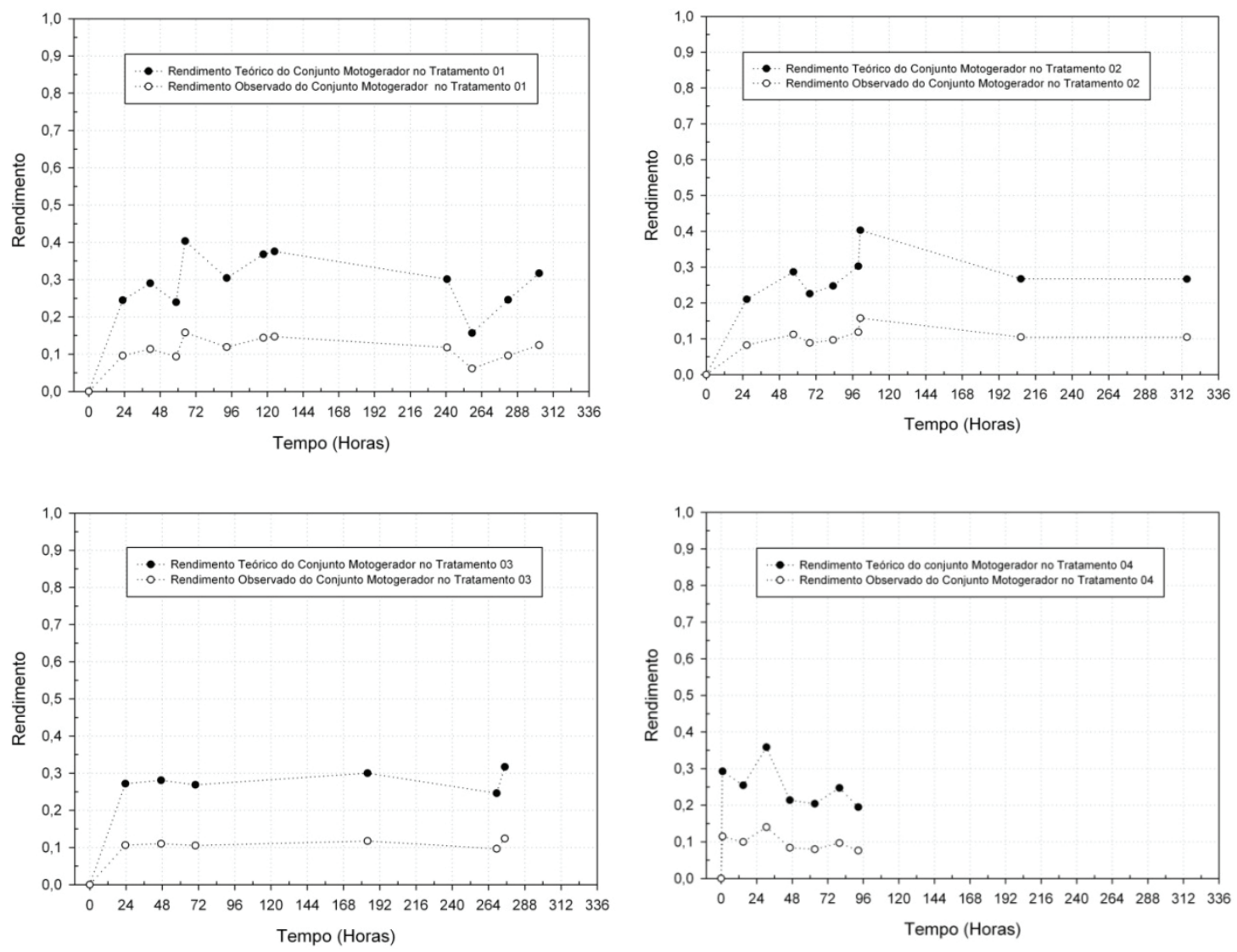

Figura 4. Representação gráfica do rendimento teórico e observado do conjunto motor gerador para cada tratamento.

\section{CONCLUSÕES}

- Com base nos resultados encontrados podese concluir queA tensão, corrente e potência média geradas pelo sistema motor gerador, durante o período dos testes preliminares, (amaciamento do conjunto motor gerador) foram $253 \mathrm{~V}, 99 \mathrm{~A}$ e $22 \mathrm{kVA}$;

- A rotação, a temperatura do fluido refrigerante e do óleo lubrificante do motor não apresentaram variações significativas para nenhum dos tratamentos de filtragem do biogás, caracterizando assim uma boa condição para o perfeito funcionamento do motor;

- A análise física e química do lubrificante não apresentou diferença entre os tratamentos e a testemunha (óleo limpo), exceto os insolúveis em pentano, que reduziram para ambos os tratamentos, quando comparados com o óleo limpo;

- Os sistemas de filtragem, em média, reduziram as emissões de $\mathrm{CH}_{4}$ e $\mathrm{SO}_{2}$ do conjunto motor gerador e mantiveram constantes as emissões de $\mathrm{H}_{2} \mathrm{~S}$, sendo que os demais gases não apresentaram resultados conclusivos;

- O desgaste e aditivação apresentaramse normais, não apresentando diferença significativa entre os tratamentos e a testemunha, constatando-se apenas uma pequena anormalidade visual no primeiro cilindro do motor, devido ao desalinhamento da biela;

- A filtragem com hidróxido de cálcio possibilitou o maior rendimento médio teórico e observado do conjunto motor gerador, que foi, respectivamente, de $29 \%$ e $12 \%$.

\section{REVENG}




\section{AGRADECIMENTOS}

Os autores agradecem a FAPEMIG, pelo apoio financeiro, a equipe do Portal do Agronegócio, ao Dr Ediney Magalhães e demais colegas e amigos que contribuíram de forma direta ou indireta na elaboração e execução do projeto.

\section{REFERÊNCIAS BIBLIOGRÁFICAS}

\section{ABNT- Associação Brasileira de Normas Técnicas}

NBR 11341:2008 Derivados de petróleo - Determinação dos pontos de fulgor e de combustível em vaso aberto Cleveland.

NBR 14448:2009 Produtos de petróleo -Determinação do número de acidez pelo método de titulação potenciométrica.

NBR 14953:2007 Óleos lubrificantes usados - Determinação de insolúveis.

NBR 14236:2006 Produtos de petróleo e materiais betuminosos - Determinação do teor de água por destilação.

ASTM- American Society for Testing and Materials

ASTM D445 - 09 Standard Test Method for Kinematic Viscosity of Transparent and Opaque Liquids (and Calculation of Dynamic Viscosity).

ASTM D664 - 09a Standard Test Method for Acid Number of Petroleum Products by Potentiometric Titration.

ASTM D893-97(2002)e1 Standard Test Method for Insolubles In Used Lubricating Oils.

ASTM D92 - 05a Standard Test Method for Flash and Fire Points by Cleveland Open Cup Tester.

ASTM D95 - 05e1 Standard Test
Method for Water in Petroleum Products and Bituminous Materials by Distillation.

Cacua, K.; Amell, A.S. e Cadavid, F. Effects of oxygen enriched air on the operation and performance of a diesel biogas dual fuel engine.

Biomass and Bioenergy, 2012.

Cervi, R.G.; Esperancini, M.S.T. e Bueno, O.C. Viabilidade econômica da utilização do biogás produzido em granja suínícola para geração de energia elétrica. Engenharia Agrícola, v.30, n.5, p.831-844. 2010.

- Viabilidad económica de la utilización de biogás para la conversión en energía eléctrica. Información Tecnológica, v.22, n.3, p.3-14. 2011.

Ferrarez, A.H.; Oliveira Filho, D. e Teixeira, C.A. Independência energética de granja suinícola a partir do uso de biogás. Engenharia na agricultura, v.18, n.3, p.248-257. 2010.

Gomes, F.P. Curso de estatística experimental. São Paulo: Nobel, 12a Ed., 1990. 467p.

Gonzalez, J.M.M.; Junco, B.J.A. e Pinilla, L.A.S. Evaluación experimental de un motor encendido por chispa que utiliza biogás como combustible. Revista Ingeniería e Investigación, v.28, n.2, p.131-141. 2008.

Holm-Nielsen, J.B.; Al-Seadi, T. e OleskowiczPopiel, P. The future of anaerobic digestion and biogas utilization. Bioresource Technology, v.100, p.5478-5484. 2009.

Koelsch, R.K.; Jewell, W.J. e R.J. Cummings Cogeneration of Electricity and Heat from Biogas.

ASAE-American Society of Agricultural Enginniers - Applied Engineering In Agriculture, v.2, n.2, p.220-224 e 227. 1986.

Konzen, E.A. Manejo e utilização de dejetos de suínos. Embrapa Suínos e Aves. Concordia, SC Brasil. p.188. 1983. (Circular técnico). n.6.

Lacour, S.; Chinese, T.; Alkadee, D.; Perilhon, C. e 
Descombes, G. Energy and environmental balance of biogas for dual-fuel mobile applications. Renewable and Sustainable Energy Reviews, v.16, p.1745-1753. 2012.

Marques, C.A. Microgeração de energia elétrica em uma propriedade rural utilizando biogás como fonte primária de energia elétrica. (Dissertação de mestrado). CCET - Centro de Ciências Exatas e Tecnológicas, UNIOESTE - Universidade Estadual do Oeste do Paraná, Cascavel-PR, 2012.

Martins, F.M. e Oliveira, P.A.V. Análise econômica da geração de energia elétrica a partir do biogás na suinocultura. Engenharia Agrícola, v.31, n.3, p.477-486. 2011.

Oliveira, P.A.V. Manual de manejo e utilização dos dejetos de suínos. Embrapa Suínos e Aves. Concordia, SC - Brasil. p.188. 1993. (Circular técnico). n.27.

Porpatham, E.; Ramesh, E. e Nagalingam, B. Investigation on the effect of concentration of methane in biogas when used as a fuel for a spark ignition engine. Fuel, v.87, p.1651-1659. 2008.

Souza, J. Desempenho de um motor de combustão interna ciclo Otto operando com gás natural e Biogás. (Dissertação de mestrado). CCET - Centro de Ciências Exatas e Tecnológicas, UNIOESTE - Universidade Estadual do Oeste do Paraná, Cascavel-PR, 2004. 60p.

Souza, R.G.; Silva, F.M. e Bastos, A.C. Desempenho de um conjunto motor gerador adaptado a biogás. Ciência e Agrotecnologia, v.34, n.1, p.190-195. 2010.

Souza, S.M.N.; Pereira, W.C.; Nogueira, C.E.C.; Pavan, A.A. e Sordi, A. Custo da eletricidade gerada em conjunto motor gerador utilizando biogás da suinocultura. Acta Scientiarum Technology, v.26, n.2, p.127-133. 2004.

Varnero, M.T.; Carú, M.; K.Galleguillos e P.Achondo. Tecnologías disponibles para la purificación de biogás usado en la generación eléctrica. Información Tecnológica, v.23, n.2, p.31-40. 2012. 